\title{
BMJ Open What are healthcare workers' preferences for hand hygiene interventions? A discrete choice experiment
}

\author{
Wenlin Chen (D) , ${ }^{1}$ Chung-Li Tseng ${ }^{2}$
}

To cite: Chen W, Tseng C-L. What are healthcare workers' preferences for hand hygiene interventions? A discrete choice experiment. BMJ Open 2021;11:e052195. doi:10.1136/ bmjopen-2021-052195

- Prepublication history for this paper is available online. To view these files, please visit the journal online (http://dx.doi org/10.1136/bmjopen-2021052195).

Received 09 April 2021 Accepted 20 October 2021
Check for updates

(C) Author(s) (or their employer(s)) 2021. Re-use permitted under CC BY-NC. No commercial re-use. See rights and permissions. Published by BMJ.

${ }^{1}$ School of Management and Economics, University of Electronic Science and Technology of China, Chengdu, Sichuan, China

${ }^{2}$ Business School, University of New South Wales, Sydney, New South Wales, Australia

Correspondence to Dr Wenlin Chen; wenlinchen@uestc.edu.cn

\section{ABSTRACT}

Objectives To understand the key attributes in designing effective interventions for improving healthcare workers' (HCWs') hand hygiene compliance and HCWs' preference for these attributes.

Design A discrete choice experiment (DCE) was conducted with five attributes extracted from the framework of Total Quality Management that can be applied in the design of hand hygiene interventions. They were hand hygiene monitoring, open discussion, message framing, resources accessibility and top management involvement. An addition attribute, peer hand hygiene performance, was considered as a contextual factor. Data were analysed by a conditional logit model to evaluate how these attributes impact HCWs' hand hygiene compliance.

Setting The DCE was conducted with participants from a university hospital in Taichung.

Participants HCWs involved in daily patient-care activities ( $\mathrm{N}=387$ ).

Results To enhance their compliance, HCWs had strong and consistent preferences in having open discussion of hand hygiene problems ( $\beta=0.4977, p<0.001$ ), easy access to hand hygiene resources ( $\beta=0.5633$ $, p<0.001)$ and top management involvement $(\beta=0.4779, p<0.001)$. For hand hygiene monitoring ( $\beta=-0.1259, p<0.1)$, HCWs preferred to be monitored by infection control staff over their department head if their peer hand hygiene performance was low. On the other hand, when the peer performance was high, monitoring by their department head could improve their hand hygiene compliance. Similarly, how educational messages were framed impacted compliance and also depended on the peer hand hygiene performance. When the peer performance was low, HCWs were more likely to increase their compliance in reaction to loss-framed educational messages $(\beta=0.1211, p<0.1)$. When the peer performance was high, gain-framed messages that focus on the benefit of compliance were more effective in inducing compliance.

Conclusions Each intervention design has its unique impact on HCWs' hand hygiene compliant behaviour. The proposed approach can be used to evaluate HCWs' preference and compliance of an intervention before it is implemented.

\section{Strengths and limitations of this study}

- A Total Quality Management framework, which has been widely used in improving service quality, was applied to design hand hygiene interventions.

- Five attributes about intervention design and one attribute about contextual factor were identified for the discrete choice experiment.

- The proposed approach can be used to evaluate healthcare workers' (HCWs') preference and compliance of an intervention before it is implemented.

- Participants were randomly selected from a specific hospital, and therefore the findings might not be generalised to other settings.

- There might be some discrepancies between HCWs' preferences in real life and those stated in the discrete choice experiment.

\section{INTRODUCTION}

Patient safety is one of the most important indicators of healthcare quality. A serious threat to patient safety comes from healthcareassociated infections (HCAIs). According to a report published by WHO, the level of HCAI prevalence in high-income countries such as Germany, The Netherlands and the UK ranged from $3.5 \%$ to $12 \%$. In low-income and middle-income countries, the level of prevalence varied from $5.7 \%$ to $19.1 \%$. $^{1}$

A leading cause of HCAIs is antibioticresistant bacteria (ARB), such as methicillinresistant Staphylococcus aureus and vancomycin-resistant enterococci, which are transmitted among hospitalised patients via healthcare workers' (HCWs') contaminated hands. ${ }^{2}$ For this reason, hand hygiene conducted by HCWs plays an extremely important role in reducing the spread of $\mathrm{ARB}$ and the probability for patients to get infected as well. ${ }^{3-5}$

Due to the importance of hand hygiene in HCAI control, formal written guidelines on HCWs' handwashing practices have been 
published by the Center for Disease Control and Prevention since 1975. In addition to that, the Association for Professionals in Infection Control, the Healthcare Infection Control Practices Advisory Committee and the WHO have also provided guidelines about hand hygiene. Recently, WHO has launched a global 'save lives: clean your hands' campaign to motivate healthcare facilities to improve HCWs' hand hygiene compliance since 2009.

Though there are guidelines specifying when HCWs need to wash their hands, what products and techniques should be used, and how HCW hands should be washed, ${ }^{6}$ studies show that the average hand hygiene compliance is still low. In some cases, compliance is even lower than $50 \% .^{7-11}$

A variety of hand hygiene interventions have been carried out to improve HCWs' hand hygiene compliance, however, their effectiveness varies. ${ }^{12-16}$ For instance, one intervention may improve HCWs' compliance significantly in one setting ${ }^{17}$ but fail to work in another. ${ }^{18}$ To design effective interventions, it is imperative to understand HCWs' willingness to comply with the interventions, that is, their preferences for interventions and the contextual factors influencing the preferences. However, little research has been conducted in this area.

The aim of this study is to identify the key attributes of the implementation of hand hygiene interventions and to test how HCWs' preference may vary subject to contextual factors. To identify the key attributes, we conducted comprehensive literature review in management and focused on the framework of Total Quality Management (TQM). As an integrative management philosophy developed in the late 1980s, TQM intends to improve the quality of products and processes through continuous improvement. ${ }^{19}{ }^{20}$ Viewing quality improvement as a driver for long-term effectiveness and survival, TQM claims that improved quality can decrease rather than increase operational costs and facilitate the achievement of organisation objectives. ${ }^{21}$

Initially adopted by the manufacturing industry, TQM has now been applied in service organisations to improve their ability to deliver services with higher quality, such as clinical quality measured in terms of the extent to which HCWs comply with standardised procedures to deal with patients' health issues. ${ }^{22-24}$ Five key attributes were identified: hand hygiene monitoring, open discussion, message framing, resources accessibility and top management involvement. We also focused on factors on work environment and chose peer hand hygiene performance as the representative contextual factor in the study.

\section{METHODS}

\section{Discrete choice experiment}

A discrete choice experiment (DCE) was conducted to measure HCWs' preferences of the key attributes of hand hygiene interventions. DCEs have been commonly used in economics and marketing to elicit individual preference to an alternative, which can be goods, services,

\begin{tabular}{|c|c|c|}
\hline Attributes & Levels & Coding \\
\hline \multirow[t]{2}{*}{$\begin{array}{l}\text { Hand hygiene } \\
\text { monitoring }\end{array}$} & $\begin{array}{l}\text { Carried out by an infection } \\
\text { control staff }\end{array}$ & -1 \\
\hline & $\begin{array}{l}\text { Carried out by the department } \\
\text { head or equivalent }\end{array}$ & 1 \\
\hline \multirow[t]{2}{*}{ Open discussion } & Not provided & -1 \\
\hline & Provided & 1 \\
\hline \multirow[t]{2}{*}{ Message framing } & Gain-framed message & -1 \\
\hline & Loss-framed message & 1 \\
\hline \multirow{2}{*}{$\begin{array}{l}\text { Accessibility to hand } \\
\text { hygiene resources }\end{array}$} & Low level of accessibility & -1 \\
\hline & High level of accessibility & 1 \\
\hline \multirow{4}{*}{$\begin{array}{l}\text { Top management } \\
\text { involvement }\end{array}$} & Never involved & $-1-1-1$ \\
\hline & Hardly involved & 001 \\
\hline & $\begin{array}{l}\text { Only involved as a reaction to } \\
\text { a crisis }\end{array}$ & 010 \\
\hline & Often involved & 100 \\
\hline \multirow{2}{*}{$\begin{array}{l}\text { The other healthcare } \\
\text { workers' hand } \\
\text { hygiene compliance }\end{array}$} & Low compliance & -1 \\
\hline & High compliance & 1 \\
\hline
\end{tabular}

policies or behaviours, under various hypothetical scenarios. In a DCE, each alternative is described by a set of attributes and levels, rather than actual situations. ${ }^{25} 26$ DCEs have been applied in the field of healthcare since early $1990 \mathrm{~s}^{27}$ to investigate patients' preferences for various treatments, ${ }^{28}{ }^{29}$ health providers ${ }^{30}$ and healthcare insurance, ${ }^{31}$ as well as evaluating HCWs' preferences for human resources policies ${ }^{32}$ and medical decisions. ${ }^{33}$ In a DCE, an individual's preference can be explained by a probability of an alternative being chosen in a given hypothetical scenario.

\section{Attributes and levels}

The first step in the development of a DCE is to identify attributes and their levels. In this study, we conducted a comprehensive literature review on the topic of TQM for the identification of relevant attributes applicable in hand hygiene interventions. Five key attributes were identified: hand hygiene monitoring, open discussion, message framing, resources accessibility and top management involvement. To address work environment factors, one additional attribute, peer hand hygiene performance, was considered as a contextual factor. ${ }^{34-37}$ The six selected attributes and levels were reviewed by five experts. The final version of attributes and levels is listed in table 1 . The weights of all the attribute levels are assigned using effect coding. The attribute levels labelled as -1 were reference levels.

\section{Questionnaire design}

As described in table 1 , a total of six experimental attributes, five with two levels and one with four levels, were identified. Therefore, in the DCE, there were 128 $\left(2^{5} \times 4\right)$ profiles in a full factorial design, resulting in 8128 


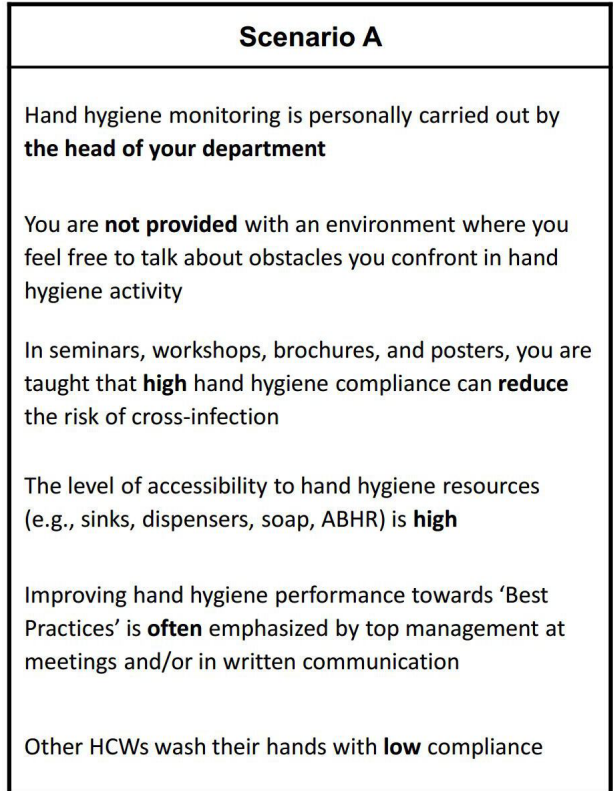

\begin{tabular}{|l|}
\hline \multicolumn{1}{|c|}{ Scenario B } \\
\hline $\begin{array}{l}\text { Hand hygiene monitoring is carried out by an infection } \\
\text { control staff }\end{array}$ \\
You are not provided with an environment where you \\
feel free to talk about obstacles you confront in hand \\
hygiene activity \\
In seminars, workshops, brochures, and posters, you are \\
taught that low hand hygiene compliance increases the \\
risk of cross-infection \\
The level of accessibility to hand hygiene resources \\
(e.g., sinks, dispensers, soap, ABHR) is high \\
Improving hand hygiene performance towards 'Best \\
Practices' is only emphasized by top management at \\
meetings and/or in written communication as a \\
reaction to a crisis \\
Other HCWs wash their hands with high compliance
\end{tabular}

In which scenario are you more willing to comply with the guideline to wash your hands?

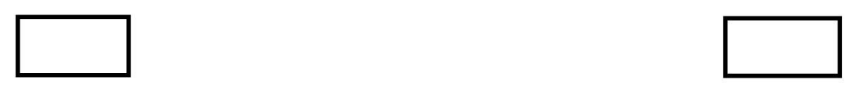

Figure 1 Example of a choice set in the discrete choice experiment. ABHR, alcohol-based hand rub; HCWs, healthcare workers.

$(128 \times 127 / 2)$ combinations of pair wise choices. However, the number of profiles was too large to be manageable for HCWs. Therefore, macros developed by Kuhfeld ${ }^{38}$ for SAS (eg, Mktruns, MktEx, ChoicEff, MktBlock) were used to reduce the number of questions. By using the macros, a statistical efficiency design was generated by minimising the predicted SEs of the estimated parameters. As a result, 32 profiles from the full factorial design were chosen and transformed into 16 choice sets (each choice set consists of 2 profiles). Figure 1 is an example of a DCE choice set with 2 profiles.

One concern in the DCE is hypothetical bias, which is defined as the discrepancies between preferences identified in DCEs and those identified in reality. A 'cheap talk' script is recommended for the purpose of reducing hypothetical bias. ${ }^{39}$ In this script, HCWs were encouraged to answer the questions as if they were making an actual decision. In addition, to avoid biases from the order in which choice questions were presented, the MktBlock macro was used to generate 12 different versions of DCE questionnaire.

The questionnaires were originally written in English. Then, they were translated into traditional Chinese by two Chinese bilinguals and translated back into English by two different English bilinguals, as recommended by Brislin $^{40}$ and Triandis. ${ }^{41}$ The translated questionnaire was presented to a few HCWs. According to their feedback, the layout of the choice sets was slightly modified to enhance the clarity and realism of the choice tasks. In addition, an example was given at the beginning of the survey to the subjects on how to answer the choice questions and help them quickly understand the choice experiments.

With respect to the sample size, studies have shown that 20-30 respondents per version of the questionnaire can provide precise parameter estimates. ${ }^{42}$ Since we had 12 versions of the questionnaire, the appropriate sample size was 240-360. Considering the response rate, 400 questionnaires in total were distributed.

\section{Patient and public involvement}

No patient involved.

\section{Participants}

Respondents were HCWs, including nurses, medical doctors, nursing students and medical students, who were involved in patient-care activities in a university hospital in Taiwan. Stratified sampling was used to randomly select eligible participants in the hospital, generating a list of 400 HCWs. A study investigator gave the name list to the head of nurses in each department and asked them to invite the HCWs on the given list to fill the questionnaires. Participation was voluntary and all participants signed an informed consent form before any study procedure.

\section{Data analysis}

Since a statistical model in the DCE is derived from the random utility theory, ${ }^{43} 44$ a HCW's utility function for each hand hygiene choice (ie, to comply with the guideline to wash their hands under a scenario) consists of both explainable and random parts. 
In this study, the explainable parts of attributes were estimated by a conditional logit model, which showed the mean change in utility value placed by the respondents assigned to the attribute levels compared with the reference level. Specifically, a conditional logistic regression for a model considering only main effects was used to evaluate the importance of the key attributes of hand hygiene interventions. In addition, a conditional logit model with interactions of peer hand hygiene performance and each hand hygiene intervention attribute was used to identify how a key intervention attribute influenced compliance was affected by peer performance.

The random parts, which included unobserved factors and errors, were assumed to be independently and identically distributed across different choices and to follow a common Gumbel distribution with the location parameter of 0 and the scale parameter of $1 .^{44}$ The data were analysed by Stata V.15.0 for Windows.

\section{RESULTS}

In total, 396 questionnaires were returned with 9 of them excluded from this study due to incompleteness or incorrectness of answers. Data from the remaining 387 questionnaires were used for the analysis. Table 2 summarises basic socio-demographic characteristics for the 387 participants. In brief, the study sample of HCWs was predominantly woman $(88.08 \%)$ and mostly nurses $(82.64 \%)$. Over $50 \%$ of the nursing staff worked in general wards, about a quarter worked in an intensive care unit and almost three quarters of the HCWs graduated from college $(74.61 \%)$. In addition, a consistency test was conducted to show the convergent validity of the DCE.

Table 3 displays the coefficients for the main-effects-only model and the model with two-way interactions. From the main-effects-only model in table 3, we found that HCWs had positive responses (comparing with corresponding references) to open discussion $(\beta=0.4512, \mathrm{p}<0.001)$, lossframed message $(\beta=0.2076, \mathrm{p}<0.001)$ and easy access to hand hygiene resources $(\beta=0.6067, \mathrm{p}<0.001)$. As for top management involvement, HCWs would be willing to comply with the guideline to wash their hands if the top management often emphasised improving the compliance towards 'Best Practice' at meetings and/or in written communication $(\beta=0.3398, \mathrm{p}<0.001)$. However, if the top management only mentioned hand hygiene in reaction to a crisis, HCWs were less willing to comply with the hand hygiene guideline $(\beta=-0.3282, \mathrm{p}<0.001)$. In addition, hand hygiene monitoring carried out by a department head made HCWs less willing to comply with the guideline to wash their hands $(\beta=-0.1417, \mathrm{p}<0.001)$.

The model with two-way interactions in table 3 indicated the moderating effect of peer hand hygiene performance on the relationship between the key intervention attributes and the willingness of compliant hand hygiene behaviour. Two of the seven interaction terms were significant: one is related to monitoring by head ( $\beta$ $=0.1538, \mathrm{p}<0.01)$ and the other is related to loss-framed
Table 2 Socio-demographic characteristics of HCWs

\begin{tabular}{|c|c|}
\hline Characteristics & $\begin{array}{l}\text { Percentage of } \\
\text { sample (\%) }\end{array}$ \\
\hline \multicolumn{2}{|l|}{ Gender } \\
\hline Male & 11.92 \\
\hline Female & 88.08 \\
\hline \multicolumn{2}{|l|}{ Type of HCW } \\
\hline Nurse & 82.64 \\
\hline Nursing student & 0.26 \\
\hline Medical doctor & 8.29 \\
\hline Medical student & 3.11 \\
\hline Other & 5.70 \\
\hline \multicolumn{2}{|l|}{ Type of ward } \\
\hline Intensive care unit & 25.44 \\
\hline General ward & 51.75 \\
\hline Other & 22.81 \\
\hline \multicolumn{2}{|l|}{ Age in years } \\
\hline$<20$ & 0.26 \\
\hline 20-25 & 26.42 \\
\hline $26-30$ & 19.95 \\
\hline $31-40$ & 42.49 \\
\hline$>40$ & 10.88 \\
\hline \multicolumn{2}{|c|}{ Years of working in hospital } \\
\hline$<1$ & 10.36 \\
\hline $1-3$ & 22.28 \\
\hline $4-8$ & 19.95 \\
\hline $9-14$ & 25.13 \\
\hline $15-20$ & 17.10 \\
\hline$>20$ & 5.18 \\
\hline \multicolumn{2}{|l|}{ Education level } \\
\hline College & 74.61 \\
\hline Master & 11.92 \\
\hline Doctor of Philosophy & 1.55 \\
\hline Other & 11.92 \\
\hline
\end{tabular}

HCWs, healthcare workers.

messaging $(\beta=-0.2237, \mathrm{p}<0.001)$. The former implies that monitoring by head became more favourable when peer hand hygiene compliance increased; equivalently, monitoring by infection control staff was more favourable when peer compliance decreased. The latter result indicated that loss-framed messages had less impact on hand hygiene compliance when peer hand hygiene compliance changed from low to high.

To further interpret the results in terms of HCWs' compliance intention, coefficients of the model with interactions were converted into probability estimates. It was predicted that there was $18.23 \%$ and $37.30 \%$ chance that an HCW from the sample would comply with the hand hygiene guideline in the baseline case when peer compliance was low and high, respectively. The baseline 


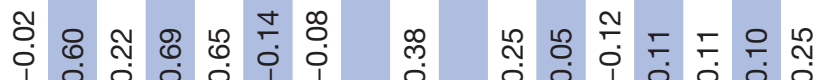

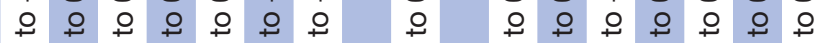

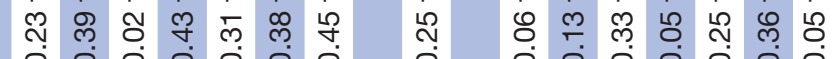

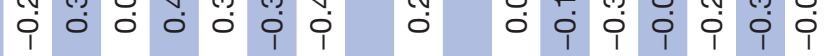

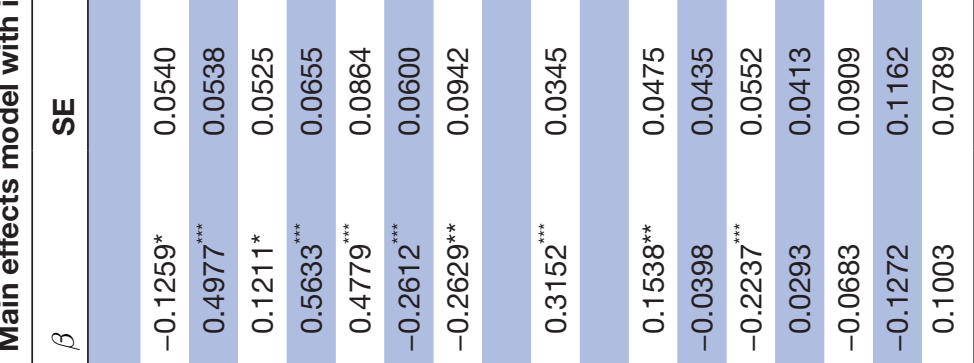

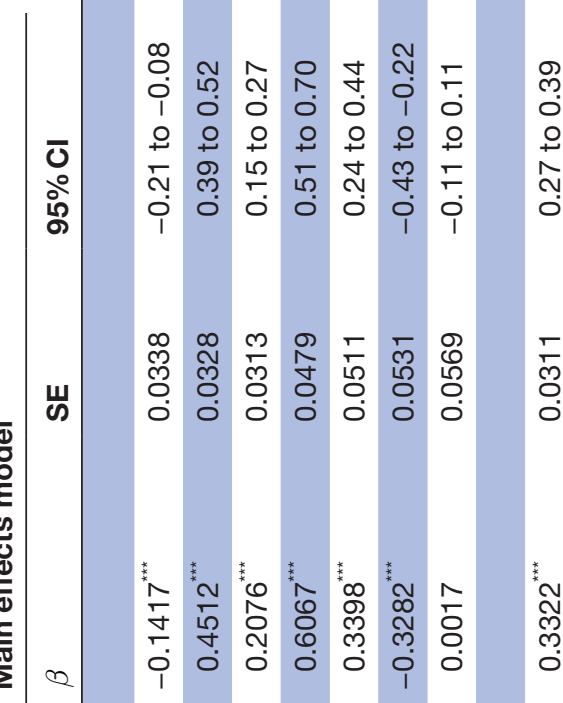

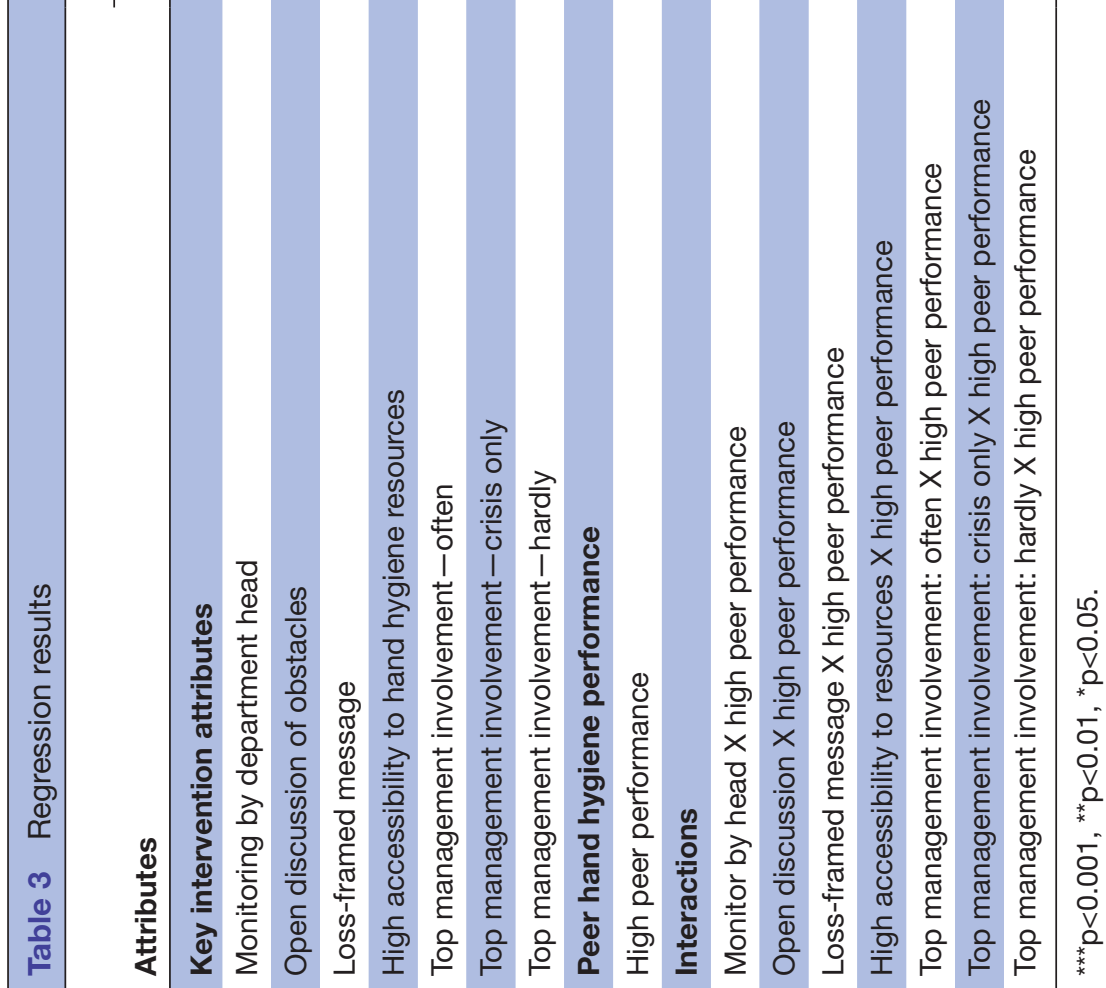




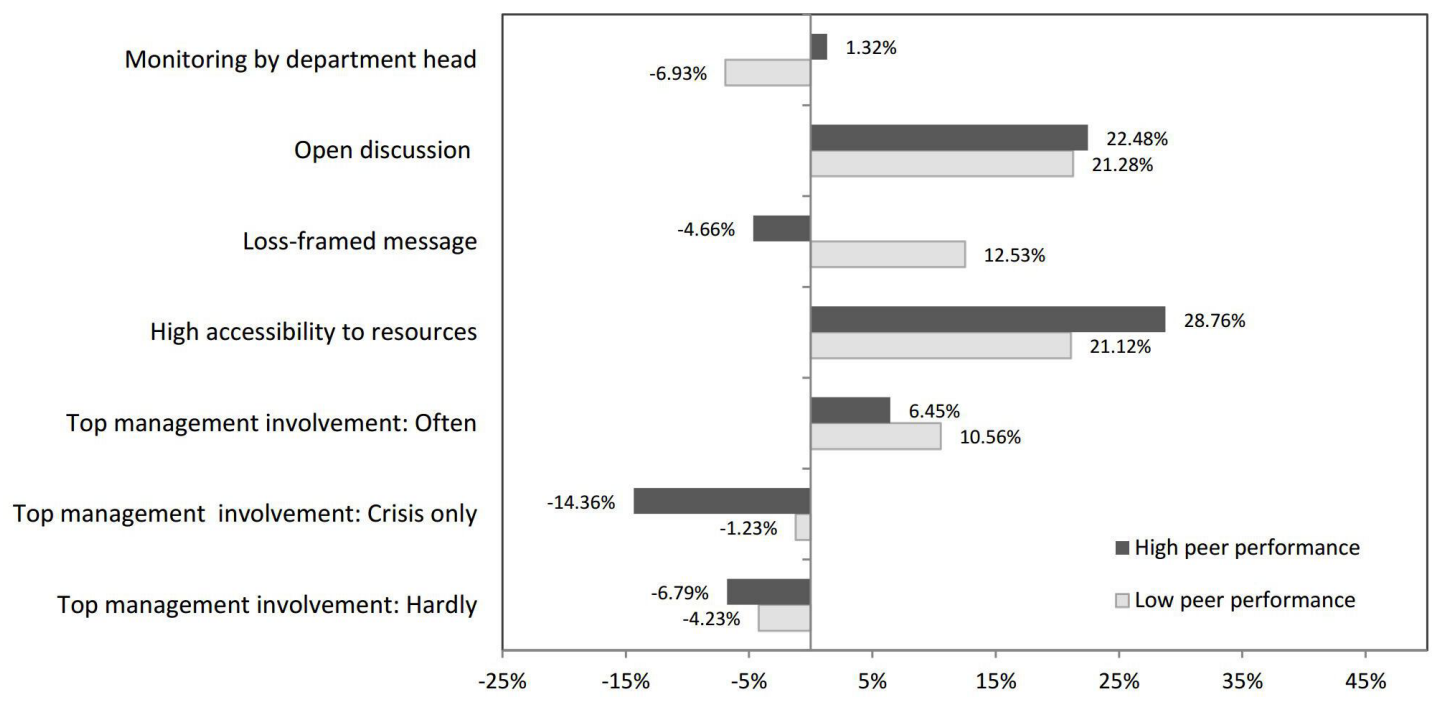

Figure 2 Change in probability of hand hygiene compliance against the baseline case with the consideration of peer hand hygiene performance.

case refers to the one where all the attributes were set to their reference levels (ie, the attributes coded with -1 in table 1).

Figure 2 charts the marginal changes in the predicted probability that the HCWs were compliant with the guideline by changing each attribute level, one at a time, against to the baseline case. Two probabilities, one under high and the other under low peer compliance, are reported for each attribute. Each bar in figure 2 shows the effect of the corresponding attribute on the HCWs' predicted compliance, with its size indicating the level of influence. A leftward bar from the baseline represents a reduction in the probability of compliance, while a rightward bar indicates a positive effect.

Figure 2 shows that when peer hand hygiene performance was low, the key intervention attributes that could effectively enhance compliance were providing opportunities for open discussion and easy access to hand hygiene resources, with each increased around $21 \%$ of the compliance probability from the baseline. Using loss-framing messages could improve the compliance probability by about $13 \%$. The often involvement of the top management could increase the compliance probability by about $11 \%$.

Figure 2 also displays the changes in probability when peer hand hygiene performance was high, under which easy access to hand hygiene resources, providing opportunities for open discussion and top management involvement could as well increase compliance. Hand hygiene monitoring carried out by the head of a department decreased compliance probability by about $7 \%$ when peer performance was low but slightly increased the probability by $1 \%$ when others were maintaining high compliance. The framing of educational messages showed different effects with the change of peer compliance: loss framing decreased compliance probability by around 5\% when peer compliance was high. When the top management hardly involved or only involved as a reaction to a crisis, the probability for HCWs to comply with the guideline to wash their hands was lower than that in the base case when there was no top management involved.

\section{DISCUSSION}

This study explored HCWs' preferences for key hand hygiene intervention attributes based on a TQM framework. We find that HCWs had consistent preferences for open discussion on handwashing obstacles, easy access to hand hygiene resources and top management involvement, regardless of the contextual factor of peer hand hygiene performance. For the other two intervention attributes, that is, hand hygiene monitoring and message framing, HCWs' preference varied according to peer compliance.

In this study, the attribute of peer hand hygiene performance was represented by a statement: 'other HCWs wash their hands with low (or high) compliance'. In this context, peer performance may be reasoned as a proximity of the general hand hygiene compliance of the workplace. With this interpretation, our result sheds light on what hospitals can do to improve HCWs' compliance when the overall compliance is low or high. In terms of monitoring, our result suggests that HCWs believe that monitoring by infection control staff is more effective when the overall hand hygiene compliance is low in the hospital. However, when all HCWs are following guidelines, monitoring by department heads is preferred. This implies that the HCWs know how monitoring should be conducted to be effective. It may also imply that HCWs prefer more autonomy and less interference on their busy routines.

The effectiveness of message framing also depended on the contextual factor of peer hand hygiene performance. A gain-framed appeal focused on the benefit of compliance, for example, hand hygiene reduces the risk of cross infection. On the contrary, a loss-framed 
message emphasised the negative consequences of failing to wash hands with high compliance, for example, failing to maintain hand hygiene increases the risk of cross infection. ${ }^{45}$ Our finding is consistent with prospect-theoretical reasoning to suggest that emphasising losses are more motivating than focusing on gains for high-risk tasks (eg, low overall compliance indicates high probabilities for patients to get infected and for HCWs' hand to be contaminated), whereas gain-framed messages are more effective for low-risks tasks (eg, high overall compliance indicates low probabilities for patients to get infected and for HCWs' hand to be contaminated). ${ }^{46}$

We found that HCWs strongly preferred open discussion of hand hygiene obstacles, regardless of peer performance. The positive role of open discussion has also been found in many other studies related to quality improvement. ${ }^{47-49}$ A key for the success is to help HCWs realise that the purpose of open discussion is not to punish or judge non-compliant behaviours. Instead, it is to find possible solutions, which can be found if they talk freely about the obstacles confronted in their hand hygiene activities. Providing easy access to hand hygiene resources, for example, soap dispensers, automated sinks, alcohol-based hand rubs and antiseptic lotions, was fundamental in enabling HCWs to carry out hand hygiene tasks. One possible explanation is that when provided with easy access to the resources, HCWs would become more confident in their work, motivating them to exert more effort in hand hygiene. ${ }^{50-53}$ Top management involvement is also important for successful quality management. ${ }^{54-57}$ This is because it helps to create a safety culture in the working environment and provide support to HCWs so that HCWs can be led and guided to minimise and eliminate the gaps between their current hand hygiene performance and the best practice. ${ }^{58} 59$ The safety culture and the support can only be recognised by HCWs when top management often encourages them to improve their compliance toward 'Best Practice'. If this issue is only emphasised by top management as a reaction to a crisis, the compliance cannot be improved. Our result shows that it may be even worse than the one without any top management involvement.

The main strength of this work is that it provides an initial and important first step in understanding HCWs' preferences for hand hygiene intervention design from a managerial framework with the consideration of contextual factors. There are several limitations in this study. The first limitation is the hypothetical bias generated from the DCE method. It was not clear whether HCWs had the same preferences in real life as they stated in the DCE. In addition, the data were collected from a single hospital, which made the findings difficult to be generalised to other settings. However, this study provided valuable preliminary information about the understanding of HCWs' preferences to the key intervention attributes. In the future, hospitals could follow the similar approach to examine the effectiveness of the interventions about to be implemented in their own settings.

\section{CONCLUSION}

This study introduces five key hand hygiene intervention attributes based on a TQM framework. These five intervention attributes are commonly practiced in hospitals. We demonstrate that each attribute had a significant impact on HCWs' hand hygiene compliant behaviour, which was moderated by peer compliance. It is critical for decision-makers to understand HCWs' preferences for these intervention attributes and under what circumstances they are effective.

Acknowledgements The authors would like to thank the participants who gave their time to complete a discrete choice questionnaire. They also would like to thank Dr Chi-Chang Chang, a professor at the Chung Shan Medical University, and Dr Choi-Hsiang Lee, the Vice President of Chung Shan Medical University Hospital, for their support of this project.

Contributors WC contributed to the design, data collection, analysis and interpretation of data and drafting the manuscript. C-LT contributed to the design, analysis, interpretation and revising the manuscript. All authors gave final approval of the submitted manuscript. WC: guarantor.

Funding The study was approved by the Human Research Ethics Advisory (HREA) Panel of the Business School at the University of New South Wales (UNSW), Australia (Approval No. 146023) and the Institutional Review Board (IRB), Chung Shan Medical University Hospital (CSMUH), Taichung (Approval No. CS14091) in 2014. This work was supported in part by a grant from the National Natural Science Foundation of China (grant number: 71902017).

Competing interests None declared.

Patient and public involvement Patients and/or the public were not involved in the design, or conduct, or reporting, or dissemination plans of this research.

Patient consent for publication Not applicable.

Provenance and peer review Not commissioned; externally peer reviewed.

Data availability statement Data are available upon reasonable request.

Open access This is an open access article distributed in accordance with the Creative Commons Attribution Non Commercial (CC BY-NC 4.0) license, which permits others to distribute, remix, adapt, build upon this work non-commercially, and license their derivative works on different terms, provided the original work is properly cited, appropriate credit is given, any changes made indicated, and the use is non-commercial. See: http://creativecommons.org/licenses/by-nc/4.0/.

ORCID iD

Wenlin Chen http://orcid.org/0000-0001-9835-2968

\section{REFERENCES}

1 WHO. Report on the burden of endemic health care-associated infection worldwide. Geneva, Switzerland: Clean Care is Safer Care, 2011.

2 van Kleef E, Robotham JV, Jit M, et al. Modelling the transmission of healthcare associated infections: a systematic review. BMC Infect Dis 2013;13:1-13.

3 Conly JM, Hill S, Ross J, et al. Handwashing practices in an intensive care unit: the effects of an educational program and its relationship to infection rates. Am J Infect Control 1989;17:330-9.

4 Pessoa-Silva CL, Hugonnet S, Pfister R, et al. Reduction of health care associated infection risk in neonates by successful hand hygiene promotion. Pediatrics 2007;120:e382-90.

5 Septimus E, Weinstein RA, Perl TM, et al. Approaches for preventing healthcare-associated infections: go long or go wide? Infect Control Hosp Epidemiol 2014;35:797-801. 
6 WHO. Who guidelines on hand hygiene in health care: first global patient safety challenge. Geneva, Switzerland: Clean Care is Safer Care, 2009

7 Salama MF, Jamal WY, Mousa HA, et al. The effect of hand hygiene compliance on hospital-acquired infections in an ICU setting in a Kuwaiti teaching hospital. $J$ Infect Public Health 2013;6:27-34.

8 Ho M-lin, Seto W-hong, Wong L-chin, et al. Effectiveness of multifaceted hand hygiene interventions in long-term care facilities in Hong Kong: a cluster-randomized controlled trial. Infect Control Hosp Epidemiol 2012;33:761-7.

9 Reisinger HS, Perencevich EN, Morgan DJ, et al. Improving hand hygiene compliance with point-of-use reminder signs designed using theoretically grounded messages. Infect Control Hosp Epidemiol 2014;35:593-4.

10 Chen Y-C, Sheng W-H, Wang J-T, et al. Effectiveness and limitations of hand hygiene promotion on decreasing healthcare-associated infections. PLoS One 2011;6:e27163.

11 Chen J-K, Wu K-S, Lee SS-J, et al. Impact of implementation of the world Health organization multimodal hand hygiene improvement strategy in a teaching hospital in Taiwan. Am J Infect Control 2016;44:222-7.

12 Huis $\mathrm{A}$, van Achterberg T, de Bruin M, et al. A systematic review of hand hygiene improvement strategies: a behavioural approach. Implement Sci 2012;7:1-14.

13 Gould D, Drey N. Types of interventions used to improve hand hygiene compliance and prevent healthcare associated infection. $J$ Infect Prev 2013;14:88-93.

14 Gould D, Moralejo D, Drey N, et al. Interventions to improve hand hygiene compliance in patient care: reflections on three systematic reviews for the Cochrane collaboration 2007-2017. J Infect Prev 2018:19:108-13.

15 Schweizer ML, Reisinger HS, Ohl M, et al. Searching for an optimal hand hygiene bundle: a meta-analysis. Clin Infect Dis 2014:58:248-59.

$16 \mathrm{Seo} \mathrm{H-J,} \mathrm{Sohng} \mathrm{K-Y,} \mathrm{Chang} \mathrm{SO,} \mathrm{et} \mathrm{al.} \mathrm{Interventions} \mathrm{to} \mathrm{improve} \mathrm{hand}$ hygiene compliance in emergency departments: a systematic review. $J$ Hosp Infect 2019;102:394-406.

17 Kaplan LM, McGuckin M. Increasing handwashing compliance with more accessible sinks. Infection Control 1986;7:408-10.

18 Vernon MO, Trick WE, Welbel SF, et al. Adherence with hand hygiene: does number of sinks matter? Infect Control Hosp Epidemiol 2003;24:224-5.

19 Ahire SL, Landeros R, Golhar DY. Total quality management: a literature review and an agenda for future research. Prod Oper Manag 1995:4:277-306.

20 Dahlgaard JJ, Mi Dahlgaard-Park S. Lean production, six sigma quality, TQM and company culture. The TQM Magazine 2006;18:263-81.

21 Spencer BA. Models of organization and total quality management: a comparison and critical evaluation. Acad Manage Rev 1994;19:446-71.

22 DG K, Mai F, Shan Z. Operational efficiency and patient-centered health care: a view from online physician reviews. J Oper Manag 2019;65:353-79.

23 Nair A, Nicolae M, Narasimhan R. Examining the impact of clinical quality and clinical flexibility on cardiology unit performance-Does experiential quality act as a specialized complementary asset? $J$ Oper Manag 2013;31:505-22.

24 Theokary C, Justin Ren Z. An empirical study of the relations between hospital volume, teaching status, and service quality. Prod Oper Manag 2011:20:303-18.

25 Hensher DA, Rose JM, Greene WH. Applied choice analysis: a primer. Cambridge, UK: Cambridge University Press, 2005

26 Louviere JJ, Hensher D, Swait J. Stated choice methods. Cambridge University Press, 2000.

27 Propper C. Contingent valuation of time spent on NHS waiting Lists. Econ J 1990;100:193-9.

28 Carroll FE, Gooberman-Hill R, Strange S, et al. What are patients' preferences for revision surgery after periprosthetic joint infection? a discrete choice experiment. BMJ Open 2020;10:e031645.

29 Haac BE, O'Hara NN, Mullins CD, et al. Patient preferences for venous thromboembolism prophylaxis after injury: a discrete choice experiment. BMJ Open 2017;7:e016676.

30 Rubin G, Bate A, George A, et al. Preferences for access to the GP: a discrete choice experiment. Br J Gen Pract 2006;56:743-8.

31 He AJ, Qian J, Chan W-S, AJ H, W-s C, et al. Preferences for private long-term care insurance products in a super-ageing Society: a discrete choice experiment in Hong Kong. Soc Sci Med 2021;270:113632.
32 Smitz M-F, Witter S, Lemiere C, et al. Understanding health workers' job preferences to improve rural retention in Timor-Leste: findings from a discrete choice experiment. PLoS One 2016;11:e0165940.

33 De Brún A, Flynn D, Joyce K, et al. Understanding clinicians' decisions to offer intravenous thrombolytic treatment to patients with acute ischaemic stroke: a protocol for a discrete choice experiment. BMJ Open 2014;4:e05612.

34 Zhang D, Linderman K, Schroeder RG. The moderating role of contextual factors on quality management practices. J Oper Manag 2012;30:12-23.

35 Sousa R, Voss CA. Contingency research in operations management practices. J Oper Manag 2008;26:697-713.

36 Sitkin SB, Sutcliffe KM, Schroeder RG. Distinguishing control from learning in total quality management: a contingency perspective. Acad Manage Rev 1994;19:537-64.

37 Gupta PP, Dirsmith MW, Fogarty TJ. Coordination and control in a government agency: contingency and institutional theory perspectives on GAO audits. Adm Sci Q 1994;39:264-84.

38 Marketing research methods in SAS. Experimental design, choice, conjoint and graphical techniques [program]. Cary: SAS institute, 2009.

39 Cummings RG, Taylor LO. Unbiased value estimates for environmental goods: a cheap talk design for the contingent valuation method. Am Econ Rev 1999;89:649-65.

40 Brislin RW. Back-Translation for cross-cultural research. J Cross Cult Psychol 1970;1:185-216.

41 Triandis HC. Methodological problems of comparative research. Int $\mathrm{J}$ Psychol 1976;11:155-9.

42 Viney R, Lancsar E, Louviere J. Discrete choice experiments to measure consumer preferences for health and healthcare. Expert Rev Pharmacoecon Outcomes Res 2002;2:319-26.

43 Manski CF. The structure of random utility models. Theory Decis 1977:8:229-54.

44 McFadden D. Conditional logit analysis of qualitative choice behavior. In: Zarembka P, ed. Frontiers of Econometrics. New York: Academic Press, 1973

45 O'Keefe DJ, Jensen JD. The relative persuasiveness of gain-framed and loss-framed messages for encouraging disease detection behaviors: a meta-analytic review. J Commun 2009;59:296-316.

46 Kahneman D, Tversky A. Prospect theory: an analysis of decision under risk. Econometrica 1979;47:263-92.

47 Flynn BB, Saladin B. Further evidence on the validity of the theoretical models underlying the Baldrige criteria. J Oper Manag 2001;19:617-52.

48 Tucker AL. An empirical study of system improvement by frontline employees in hospital units. M\&SOM 2007:9:492-505.

49 Ueno A. Which management practices are contributory to service quality? Int J Qual \& Reliability Mgmt 2008;25:585-603.

50 Campion MA, Medsker GJ, Higgs AC. Relations between work group characteristics and effectiveness: implications for designing effective work groups. Pers Psychol 1993;46:823-47.

51 Jung DI, Sosik JJ. Effects of group characteristics on work group performance: a longitudinal investigation. Group Dyn Theory Res Pract 1999;3:279-90.

52 Gully SM, Incalcaterra KA, Joshi A, et al. A meta-analysis of teamefficacy, potency, and performance: interdependence and level of analysis as moderators of observed relationships. J Appl Psychol 2002;87:819-32.

53 Stajkovic AD, Lee D, Nyberg AJ. Collective efficacy, group potency, and group performance: meta-analyses of their relationships, and test of a mediation model. J Appl Psychol 2009;94:814-28.

54 Spence Laschinger HK, Laschinger HKS. Effect of empowerment on professional practice environments, work satisfaction, and patient care quality: further testing the nursing Worklife model. J Nurs Care Qual 2008;23:322-30

55 Needleman J, Hassmiller S. The role of nurses in improving Hospital quality and efficiency: real-world results. Health Aff 2009;28:w625-33

56 Talib F, Rahman Z, Azam M. Best practices of total quality management implementation in health care settings. Health Mark $Q$ 2011;28:232-52.

57 RWY Y, PKC L, Yeung ACL. The relationships among leadership, goa orientation, and service quality in high-contact service industries: an empirical study. Int J Prod Econ 2013;141:452-64.

58 Barocas DA, Kulahalli CS, Ehrenfeld JM, et al. Benchmarking the use of a rapid response team by surgical services at a tertiary care hospital. J Am Coll Surg 2014;218:66-72.

59 Cotton PB, Romagnuolo J, Faigel DO, et al. The ERCP quality network: a pilot study of benchmarking practice and performance. Am J Med Qual 2013;28:256-60. 